\title{
A theoretical analysis of long-term bisphosphonate effects on trabecular bone volume and microdamage
}

\author{
Jeffry S. Nyman, ${ }^{\mathrm{a}, *}$ Oscar C. Yeh, ${ }^{\mathrm{b}}$ Scott J. Hazelwood, ${ }^{\mathrm{b}}$ and R. Bruce Martin ${ }^{\mathrm{b}}$ \\ a Biomedical Engineering Graduate Group, College of Engineering, University of California at Davis, Davis, CA 95616, USA \\ ${ }^{\mathrm{b}}$ Department of Orthopaedic Surgery, School of Medicine, University of California at Davis, Davis, CA 95616, USA
}

\begin{abstract}
Bisphosphonates increase bone mass and reduce fracture risk, but their anti-resorptive action may lead to increases in fatigue microdamage. To investigate how bisphosphonate effects influence changes in bone volume and microdamage in the long term, a strainadaptive model of bone remodeling and microdamage balance was developed for a continuum-level volume of postmenopausal trabecular bone by invoking Frost's mechanostat hypothesis. Both disuse and fatigue microdamage were assumed to stimulate the activation frequency of basic multicellular units (BMUs) such that bone remodeling served to remove excess bone mass and microdamage. Bisphosphonate effects were simulated as follows: low, intermediate, high, or complete suppression of BMU activation frequency either without a change in resorption by the BMU or with an independent decrease in resorption while the bone formation process was unaffected (i.e., formation initially exceeded resorption). Of the bisphosphonate effects, a reduction in resorption relative to formation dictated the long-term gain in bone volume while the potency of activation frequency suppression controlled the rate of gain. A plateau in the bone mass gain that typically occurs in clinical studies of bisphosphonate treatment was predicted by the model because the resultant reduction in strain forced bone formation by the BMU to decrease over time until it matched the reduction in BMU resorption. A greater suppression of activation frequency proportionally increased microdamage, but the accumulation was limited over the long term as long as remodeling was incompletely suppressed. The results of the model suggest creating bisphosphonates that provide minimal suppression of remodeling and a large decrease in BMU resorption because this would minimize damage accumulation and increase bone mass, respectively.
\end{abstract}

\section{Introduction}

With the ability to suppress osteoclastic function, bisphosphonates are being developed as drugs for treating diseases involving elevated bone remodeling, such as Paget's disease, bone metastases, and postmenopausal osteoporosis. They have a high affinity for bone mineral [1], selectively bind to hydroxyapatite exposed by resorbing activity [2], and assert their anti-resorptive effect upon coming in contact with osteoclasts [3]. A wide range in the degree of osteoclastic suppression exists for various bisphosphonate drugs [4]. Those with high potency $(>100 \times$ that of etidronate, a first generation drug) can suppress resorption at a relatively low dose, thus avoiding another biological effect of bisphosphonates, the physicochemical impairment of mineralization [4].

The suppression of bone resorption by bisphosphonates involves cellular mechanisms that may be direct, such as disruption of osteoclastic differentiation, or indirect, such as increasing inhibitory signals from cells of the osteoblastic lineage [5]. In either case, bisphosphonates inhibit activation of new basic multicellular units (BMUs). Other possible mechanisms include shortening osteoclasts' life span by inducing apoptosis [6] or decreasing their resorbing efficiency by disrupting their cytoskeleton [7]. These actions reduce the size of resorption site created by the BMU. Currently, the dominant mechanisms are not clear, but presumably depend on the chemical structure of the particular bisphosphonate.

At tissue level, mechanisms for the increase in bone mass following treatment with bisphosphonates include reduced 
remodeling space (the temporary porosity created by active BMUs) and a positive bone balance (less bone is removed than replenished at individual remodeling sites) [7]. In addition, reduced bone turnover allows more time for mineralization of existing bone, which increases bone density but not volume [7].

Although bisphosphonates reduce fracture risk for postmenopausal women [8], the associated reduction in bone remodeling has impaired the removal of microdamage and reduced the toughness of bone in a canine model $[9,10]$. Human vertebral cancellous bone with more in vivo microdamage has been observed to be weaker than similar bone with less damage [11]. Coupled with increased mineralization, which makes bone more brittle and less resistant to crack propagation, microdamage accumulation following bisphosphonate treatment of high potency may, in the long term, increase fracture risk despite an increase in bone mass.

Several studies have developed computational models that simulate bisphosphonate effects on bone mass or volume when varying such remodeling parameters as BMU activation frequency, resorption and formation periods, bone balance, and mineralization [12-15]. These models successfully approximated clinically measured changes in bone mineral density (BMD) associated with initiation of treatment. However, they did not simulate functional stimuli of remodeling that may be important in subsequent years. Three that have been identified are mechanical loading, estrogen, and microdamage.

Remodeling activation in a disuse state, when mechanical strains are reduced below physiologic levels, has been demonstrated for both cortical and trabecular bone in animal models as well as human subjects [16]. It has been hypothesized that a "mechanostat", comprised of the syncytium of osteocytes and bone lining cells, senses bone strains and activates remodeling when these strains fall below a threshold or set point [17]. This hypothesis is adopted here as the first remodeling stimulus.

Estrogen deficiency also promotes remodeling, and there is evidence that this response is closely related to the mechanostat [18]. Estrogen deficiency is associated with osteocyte apoptosis [19,20], and strain affects estrogen response elements in cells of the osteoblast lineage [21]. Thus in theory, estrogen withdrawal shifts the mechanostat set point so that normal mechanical loading elicits a disuse response. Estrogen deficiency is therefore the second remodeling stimulus in the model presented here.

Finally, as noted above, remodeling is activated by, and apparently serves to remove, bone microdamage via a pathway that again involves osteocyte apoptosis [22,23]. Thus, fatigue microdamage is the third remodeling stimulus incorporated in the model.

Using a computational model for trabecular bone remodeling that incorporates these remodeling stimuli, we investigated the following question: under what conditions of activation frequency suppression and BMU level resorption reduction will an anti-resorptive drug increase bone mass without causing an accumulation of microdamage? Specifically, the relative contributions of these bisphosphonate actions to long-term changes in bone volume and microdamage were assessed.

\section{Materials and methods}

\section{Mechanical loading}

A model by Hazelwood et al. [24] was modified to simulate adaptive remodeling in a $1 \mathrm{~cm}^{3}$ representative volume (RV) of trabecular bone (Fig. 1A) under uniaxial cyclic loading with a maximum stress $(\sigma)$ of $1 \mathrm{MPa}$ (Table $1)$. The continuum-level elastic modulus $(E)$ or apparent stiffness of this RV was assumed to be proportional to its bone volume fraction $(\mathrm{BV} / \mathrm{TV})$ as follows:

$E=E_{0} \times(\mathrm{BV} / \mathrm{TV})^{b}$

Here, $E_{0}$ is a tissue modulus calculated from an empirically derived relationship between bone stiffness and apparent

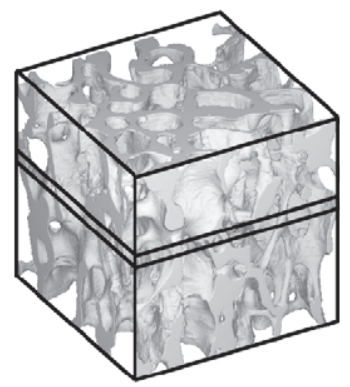

A

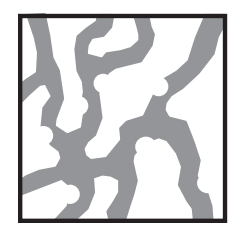

B

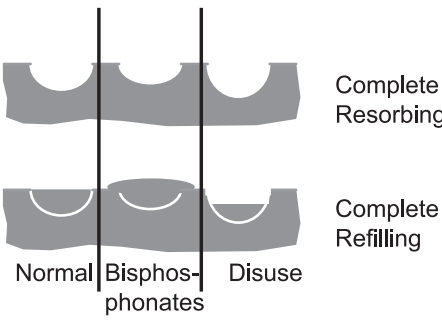

C

Fig. 1. A representative volume of bone (A) was subjected to cyclic loading, and bone remodeling was tracked within a representative cross-section (B). At the BMU level, the ratio of resorption to formation was equal to 1 under normal conditions, greater than 1 with normal bisphosphonate treatment, and less than 1 when disuse conditions exist (C). 
Table 1

Nomenclature and description of the model state variables and parameters with values obtained from simulations of premenopausal trabecular and postmenopausal trabecular bone remodeling as described in the text

\begin{tabular}{|c|c|c|c|}
\hline $\begin{array}{l}\text { State variable } \\
\text { or parameter }^{\mathrm{a}}\end{array}$ & Description & $\begin{array}{l}\text { Premenopausal } \\
\text { trabecular } \\
\text { bone }\end{array}$ & $\begin{array}{l}\text { 15-year } \\
\text { postmenopausal }\end{array}$ \\
\hline $\mathrm{E}, \mathrm{MPa}$ & Elastic modulus & 1993 & 1708 \\
\hline $\mathrm{BV} / \mathrm{TV}$ & $\begin{array}{l}\text { Bone volume } \\
\text { fraction }\end{array}$ & 0.220 & 0.196 \\
\hline$p$ & Porosity & 0.780 & 0.804 \\
\hline$\varepsilon\left(10^{-6}\right)$ & Microstrain & -502 & -585 \\
\hline$\Phi\left(10^{-10}\right)$ & Loading potential & 1.902 & 3.521 \\
\hline $\begin{array}{l}\text { Cr.S.Dn } \\
\qquad\left(\mathrm{mm} \mathrm{mm}^{-2}\right)\end{array}$ & $\begin{array}{l}\text { Total crack length } \\
\text { per section area }\end{array}$ & 0.0671 & 0.0879 \\
\hline $\begin{array}{l}\text { Ac.f } \\
\qquad\left(\# \text { day }^{-1} \mathrm{~mm}^{-2}\right)\end{array}$ & $\begin{array}{l}\text { BMUs appearing } \\
\text { in representative } \\
\text { section per day }\end{array}$ & 0.0111 & 0.0156 \\
\hline $\begin{array}{l}\text { N.F.BMU } \\
\qquad\left(\# \mathrm{~mm}^{-2}\right)\end{array}$ & $\begin{array}{l}\text { Number of } \\
\text { refilling sites }\end{array}$ & 0.708 & 1.000 \\
\hline $\begin{array}{l}\text { N.Rs.BMU } \\
\qquad\left(\# \mathrm{~mm}^{-2}\right)\end{array}$ & $\begin{array}{l}\text { Number of } \\
\text { resorbing sites }\end{array}$ & 0.277 & 0.391 \\
\hline $\mathrm{BS} / \mathrm{TA}$ & $\begin{array}{l}\text { Bone surface area } \\
\text { per section area }\end{array}$ & 2.37 & 2.16 \\
\hline Ac.f $\left(\right.$ year $\left.^{-1}\right)$ & $\begin{array}{l}\text { Approximated } \\
\text { mineralizing } \\
\text { surface fraction } \\
\text { per formation } \\
\text { period }\end{array}$ & 0.254 & $0.395^{\mathrm{b}}$ \\
\hline$\Phi_{0}$ & Disuse threshold & 1.875 & 3.469 \\
\hline$R_{\mathrm{L}}$ & $\begin{array}{l}\text { Load cycles } \\
\text { per day }\end{array}$ & 3000 & 3000 \\
\hline$F_{\mathrm{s}}$ & $\begin{array}{l}\text { Damage removal } \\
\text { specificity factor }\end{array}$ & 5 & 5 \\
\hline FAr $\left(\mathrm{mm}^{2}\right)$ & $\begin{array}{l}\text { BMU refilling } \\
\text { area }^{c}\end{array}$ & 0.014176 & 0.014176 \\
\hline Rs.Ar $\left(\mathrm{mm}^{2}\right)$ & $\begin{array}{l}\text { BMU resorption } \\
\text { area }^{d}\end{array}$ & 0.014176 & 0.014176 \\
\hline FP (day) & $\begin{array}{l}\text { BMU refilling } \\
\text { period }\end{array}$ & 64 & 64 \\
\hline Rs.P (day) & $\begin{array}{l}\text { BMU resorbing } \\
\text { period }\end{array}$ & 25 & 25 \\
\hline Rv.P (day) & $\begin{array}{l}\text { BMU reversal } \\
\text { period }\end{array}$ & 5 & 5 \\
\hline
\end{tabular}

The 15-year postmenopausal values were assumed in the model at the initiation of bisphosphonate treatment.

a Initial values were obtained from the model of Hazelwood et al. [24], except initial Ac.f, which was equal to $0.01 \mathrm{BMUs} / \mathrm{day} / \mathrm{mm}^{2}$.

b Typical of postmenopausal bone [38].

${ }^{c}$ Decreases when bone is in disuse.

${ }^{\mathrm{d}}$ Decreases when bisphosphonate is active.

density $(\rho), E=5546 \rho^{1.33}$ [25], assuming $\rho$ is equal to (BV/ $\mathrm{TV}) * 2.1 \mathrm{~g} \mathrm{~cm}^{-3}$. Hence, $E_{0}$ is $14,900 \mathrm{MPa}$ and $b$ is 1.33 . Peak strain was then given by Hooke's Law as

$\varepsilon=\sigma / \varepsilon$

When modeling bone's responses to mechanical loading, it is common practice to define a loading potential or stimulus that characterizes the mechanical environment for the given boundary conditions [24,26,27]. Following this practice, the loading potential $(\Phi)$ was defined here as

$\Phi=R_{\mathrm{L}} \times \varepsilon^{q}$ where $R_{\mathrm{L}}=3000$ is the loading frequency in cycles per day, $q=4$ adjusts the relative contribution of peak strain and loading frequency to the loading potential [24], and $\varepsilon$ is the peak strain as calculated in Eq. (2).

\section{Microdamage}

Fatigue microdamage and bone remodeling were characterized in terms of histomorphometric variables observable in a representative section (RS) through the RV (Fig. 1B). The model tracked fatigue microdamage within the RS based on assumptions about damage generation by mechanical loading and its removal by remodeling. Following Martin [28], the damage removal rate was modeled as

$\mathrm{d}\left(D_{\mathrm{R}}\right) / \mathrm{d} t=$ Cr.S.Dn $\times$ Ac.f $\times$ Rs. Ar $\times F_{\mathrm{s}}$

where Cr.S.Dn $\left(\mathrm{mm} \mathrm{mm}^{-2}\right)$ is the microcrack surface density (total microcrack length in the RS), Ac.f is the number of BMUs appearing in the RS per day, Rs.Ar is the area of each completed resorption bay, and $F_{\mathrm{s}}$ (assumed to be 5) is a specificity factor accounting for targeted remodeling (i.e., spatial association between resorption spaces and microcracks is greater than what can be explained by random remodeling [29]). The damage formation rate $\mathrm{d} D_{\mathrm{F}} / \mathrm{d} t$ was assumed to be proportional to the loading potential,

$\mathrm{d}\left(D_{\mathrm{F}}\right) / \mathrm{d} t=k_{\mathrm{D}} \times \Phi$

The coefficient $k_{\mathrm{D}}=2.77 \times 10^{5} \mathrm{~mm} \mathrm{~mm}^{-2}$ was chosen to make damage formation equal damage removal under the initial remodeling conditions [24]. The use of $\Phi$ to drive damage formation was based on the observations from ex vivo bone fatigue tests: damage accumulates during cyclic loading and the number of cycles to failure is inversely proportional to the strain range raised to a power [30].

\section{Bone volume fraction}

Changes in bone volume fraction depended on the difference between the amounts of bone being added by osteoblasts and removed by osteoclasts. In the context of the $\mathrm{RS}$, one may write for the rate of change of $\mathrm{BV} / \mathrm{TV}$,

$\mathrm{d}(\mathrm{BV} / \mathrm{TV}) / \mathrm{d} t=\frac{\mathrm{FAr}}{\mathrm{FP}} \times \mathrm{N} . \mathrm{F} \cdot \mathrm{BMU}-\frac{\text { Rs.Ar }}{\text { Rs.P }} \times$ N.Rs.BMU

Here, N.F.BMU and N.Rs.BMU are the numbers of forming and resorbing sites per unit area, respectively. FAr and Rs.Ar are completed formation and resorption areas $\left(\mathrm{mm}^{2}\right)$ within the RS, and FP and Rs.P are formation and resorption periods (days), respectively, for the average BMU (Table 1). As BMUs were activated within the RS, the model tracked their individual progress through the resorption, reversal, 
and refilling phases of remodeling, thereby calculating the resulting changes in BV/TV.

\section{BMU activation}

Activation frequency of BMUs was assumed to depend on the amount of microdamage present, the existence and severity of a disuse state, and the available surface area for the initiation of new BMUs. The latter was obtained by converting $\mathrm{BV} / \mathrm{TV}$ to porosity ( $p=1-\mathrm{BV} / \mathrm{TV})$ and using an empirical relationship for bone surface per total sectional area (BS/TA) as a function of porosity [31],

$\frac{\mathrm{BS}}{\mathrm{TA}}=32.1 p-93.9 p^{2}+134 p^{3}-101 p^{4}+28.8 p^{5}$

Ac.f (as \# mm ${ }^{-2}$ day $^{-1}$ ) was calculated using hypothetical dose-response curves for BMU activation in response to disuse and microdamage (Fig. 2) and scaled by a normalized BS/TA (varied between 0 and 1) [24].

Bone mass maintains equilibrium for certain combinations of cyclic loading frequency and strain range. Based on the analysis of this relationship by Beaupré et al. [26], an equilibrium loading stimulus or threshold $\Phi_{0}$ (i.e., the mechanostat set point) was set to $1.875 \times 10^{-10}$ cycles day $^{-1}$. (For example, 3000 cycles of loading per day at a range of 500 peak microstrain maintains bone mass.) Activation frequency and bone loss were assumed to be inversely proportional to $\Phi$, when $\Phi<\Phi_{0}$. Bone loss at the BMU level occurred by reducing formation as follows

$\operatorname{FAr}=\frac{1}{2} \operatorname{FAr}_{\text {norm }}\left(1+\frac{\Phi}{\Phi_{0}}\right)$ when $\Phi<\Phi_{0}$

where $\mathrm{FAr}_{\text {norm }}\left(\mathrm{mm}^{2}\right)$ is the normal formation area. When $\Phi \geq \Phi_{0}, \mathrm{FAr}=\mathrm{FAr}_{\text {norm }}$.

Microdamage also initiates the activation of BMUs [32]. Therefore, an additional component of activation frequency was modeled as occurring in proportion to
Cr.S.Dn (Fig. 2B). Lacking data for this response function, it was again constructed by fitting a sigmoidal curve through observed ranges of values for Ac.f and Cr.S.Dn $[24,28]$

Activation frequency in trabecular bone is usually calculated as

Ac. $=\frac{\text { MS } / \mathrm{BS}}{\mathrm{FP}}$

where MS/BS is the fraction of the bone surface that is mineralizing. To present the changes in Ac.f following simulated bisphosphonate treatment that reflects this form of calculation, BMU resorption cavities were assumed to be semicircular in geometry with a cement line radius similar to a cortical bone osteon, taken to be $0.095 \mathrm{~mm}$. This radius then became the erosion cavity depth (E.De). The average mineralizing surface of a BMU was assumed to occur at the halfway point in refilling and to equal the perimeter of a semicircle (i.e., mineralizing surface equaled E.De $\times \pi / 2$ ). With this in mind, Eq. (9) was calculated as

Ac.f $=365 \times \frac{\frac{\pi}{2} \text { E.De } \times \text { N.F.BMU }}{\text { FP } \times \text { BS } / \text { TA }}$

with the units being mineralizing surface fraction per formation period measured in years. An E.De of 0.095 $\mathrm{mm}$ may understandably seem rather deep for a trabecular $\mathrm{BMU}$, but the somewhat exaggerated radius may compensate for a tendency of trabecular BMUs to be broad as well as shallow relative to osteonal BMUs [33].

\section{Simulation of estrogen-deficient remodeling}

Menopause was simulated by invoking the hypothesis that estrogen deficiency increases the strain threshold of a mediator of remodeling in marrow that causes BMUs to remove more bone than is replenished [34]. In other words, estrogen deficiency invokes the equivalent of disuse remod-

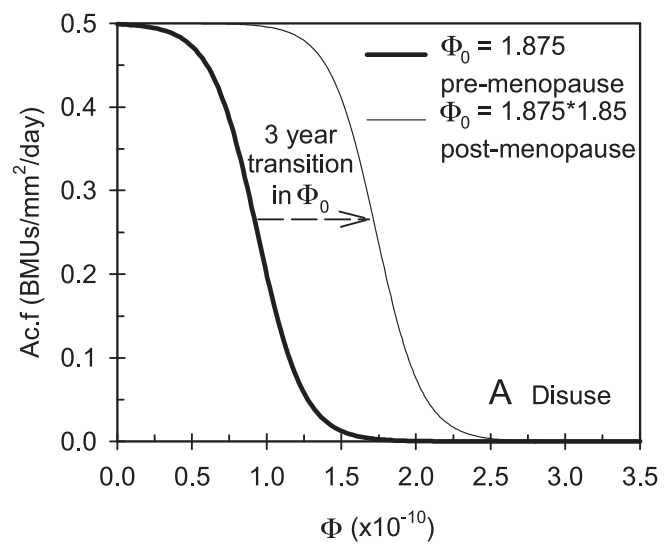

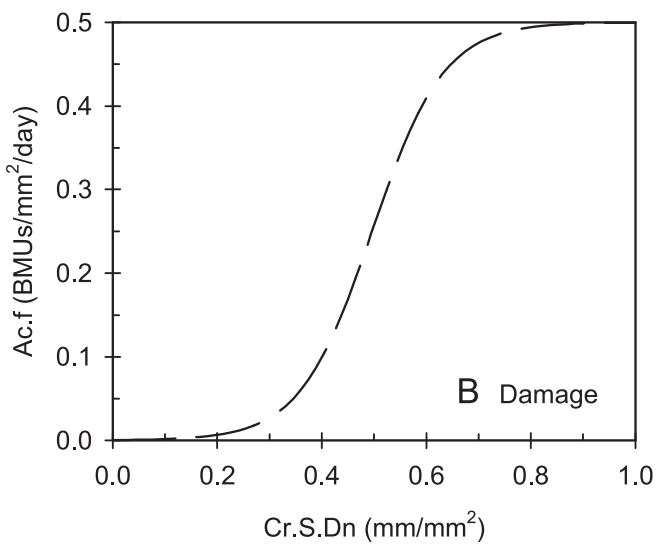

Fig. 2. Activation frequency of BMUs increased as the mechanical stimulus decreased when bone was in disuse (A). The mechanostat set point $\left(\Phi_{0}\right)$ was linearly increased by $85 \%$ over 3 years to simulate the effect of estrogen withdrawal that produces bone loss observed during menopause. Ac.f also increased as a function of the level of microdamage (B). 
eling [35]. To model this, an associated change in the mechanostat set point that would simulate the $11 \%$ average loss in BMD as observed in the lumbar spines of healthy women 5 years after menopause [36] was sought. With the model initially running in an equilibrium state (Table 1), linearly increasing $\Phi_{0}$ by $85 \%$ over a 3 -year period (Fig. $2 \mathrm{~A}$ ) achieved this goal. Using this model, 15 years of untreated estrogen-deficient remodeling were simulated. Finally, from the remodeling conditions of this 15-year postmenopausal model (Table 1), the effects of bisphosphonate treatment were studied.

\section{Simulation of bisphosphonate effects}

Bisphosphonate treatment was assumed to diminish both activation frequency [37-41] and the size of each completed resorption bay $[9,10]$. Assuming that different bisphosphonates inhibit osteoclast activation to varying degrees, a potency variable $0 \leq P \leq 1$ was introduced to quantify the effectiveness of suppressing activation frequency. Multiplying activation frequency by $(1-P)$ simulated the ability of bisphosphonate to suppress remodeling activation. Independent of this suppression, the effect of treatment on the completed size of BMU resorption cavities was simulated by reducing Rs.Ar by $1 / 6$ or $3 / 13$, which provided erosion depths within 1 standard deviation of the means as measured in transiliac bone biopsies from postmenopausal women given 5 and $10 \mathrm{mg}$ of alendronate daily, respectively, for 1 year [38]. These reductions achieved an initial bone balance ratio of 1.2 and 1.3 , respectively, because before treatment equilibrium remodeling conditions existed (i.e., FAr equaled Rs.Ar and a disuse state did not exist).

The pharmacokinetic properties of bisphosphonates include the following: (1) potency of suppression depends on chemical structure and dosage; (2) the drug binds preferentially to regions of high remodeling activity, mostly sites of bone resorption; (3) uptake of the drug can saturate; and (4) the action of the drug occurs on the osteoclast $[3,42]$. Therefore, potency was modeled as a function of the numbers of resorbing sites,

$P=P_{\max }\left(1-\mathrm{e}^{-\tau_{\mathrm{s}} \times \mathrm{N} . \mathrm{Rs} . \mathrm{BMU}}\right)$

where $P_{\max }$ and $\tau_{\mathrm{s}}$ are suppression coefficients. Conceptually, both coefficients reflect the dosage and structure of the bisphosphonate (i.e., high dose alendronate would have higher $\tau_{\mathrm{s}}$ and higher $P_{\max }$ than low dose etidronate). Values of $P_{\max }$ and $\tau_{\mathrm{s}}$ were chosen to provide a range of potency (high, intermediate, low) and cause reductions in activation frequency that were within 1 standard deviation of the means as measured after 1 year for daily alendronate (at 5 or $10 \mathrm{mg}$ ) and daily pamidronate (at $150 \mathrm{mg}$ ) treatment [37,39].

Bisphosphonate effects were simulated in a sensitivity analysis on the suppression coefficients and reduction in resorption area (Table 2) to study the relative contributions of activation frequency suppression and a reduction in BMU
Table 2

Sensitivity analysis of bisphosphonate effects simulated by the model

\begin{tabular}{|c|c|c|c|c|c|}
\hline & $\begin{array}{l}\text { Level of } \\
\text { suppression }\end{array}$ & $P_{\max }$ & $\tau_{\mathrm{s}}$ & $\begin{array}{l}\text { Initial } \\
\text { potency }\end{array}$ & $\begin{array}{l}\text { Initial bon } \\
\text { balance }\end{array}$ \\
\hline \multirow[t]{4}{*}{ A } & High & 1.0 & 20 & 0.9996 & 1.0 \\
\hline & Intermediate & 0.7 & 20 & 0.6997 & 1.0 \\
\hline & Intermediate & 1.0 & 5 & 0.8583 & 1.0 \\
\hline & Low & 0.7 & 5 & 0.6008 & 1.0 \\
\hline \multirow[t]{4}{*}{ B } & High & 1.0 & 20 & 0.9996 & 1.2 \\
\hline & Intermediate & 0.7 & 20 & 0.6997 & 1.2 \\
\hline & Intermediate & 1.0 & 5 & 0.8583 & 1.2 \\
\hline & Low & 0.7 & 5 & 0.6008 & 1.2 \\
\hline \multirow[t]{4}{*}{$\mathrm{C}$} & High & 1.0 & 20 & 0.9996 & 1.3 \\
\hline & Intermediate & 0.7 & 20 & 0.6997 & 1.3 \\
\hline & Intermediate & 1.0 & 5 & 0.8583 & 1.3 \\
\hline & Low & 0.7 & 5 & 0.6008 & 1.3 \\
\hline
\end{tabular}

level resorption to changes in bone volume and microdamage. All simulations were programmed in FORTRAN 77 and run on a UNIX workstation (Ultra 10, Sun Microsystems, Santa Clara, CA). The time step was 1 day. Because bisphosphonates are quickly taken up by the skeleton, their effects were invoked on day 0 [42].

\section{Results}

As the potency of activation frequency suppression increased, the model predicted increasing gains in bone volume over the first 3 months of treatment (Fig. 3A). These represented varying degrees of remodeling space recovery (i.e., porosity due to active BMUs fills in with mineralized bone). If treatment completely stopped remodeling, the ensuing full recovery of the model's remodeling space increased BV/TV by $5.27 \%$. If the resorption area was unaffected and remodeling was not completely inhibited, the recovered BV/TV decayed over a period of several years (lower curves in Fig. 3A).

When bisphosphonate treatment reduced resorption area as well as activation frequency, the model predicted not only the short-term increase in BV/TV (due to the loss in remodeling space) but also a substantial additional increase (Figs. 3B and 3C) that plateaus over the long term due to an improved bone balance ratio ( $\mathrm{FAr} / \mathrm{Rs}$. Ar $>1)$ in each BMU. When the initial bone balance ratio was 1.2 (resorption area reduced by $1 / 6$ ) or 1.3 (resorption area reduced by $3 / 13$ ), the model simulated the rate of increase in bone volume that paralleled the increases in BMD observed by Tonino et al. [43] using alendronate doses of 5 or $10 \mathrm{mg} \mathrm{day}^{-1}$, respectively. Greater potency of activation frequency suppression slowed the rate of this secondary gain in bone volume because there were fewer BMUs (Fig. 5) working to add bone.

The model predicted that microdamage would increase linearly without limit if the activation frequency was completely suppressed, as would be expected, but limited microdamage accumulation was predicted if remodeling 

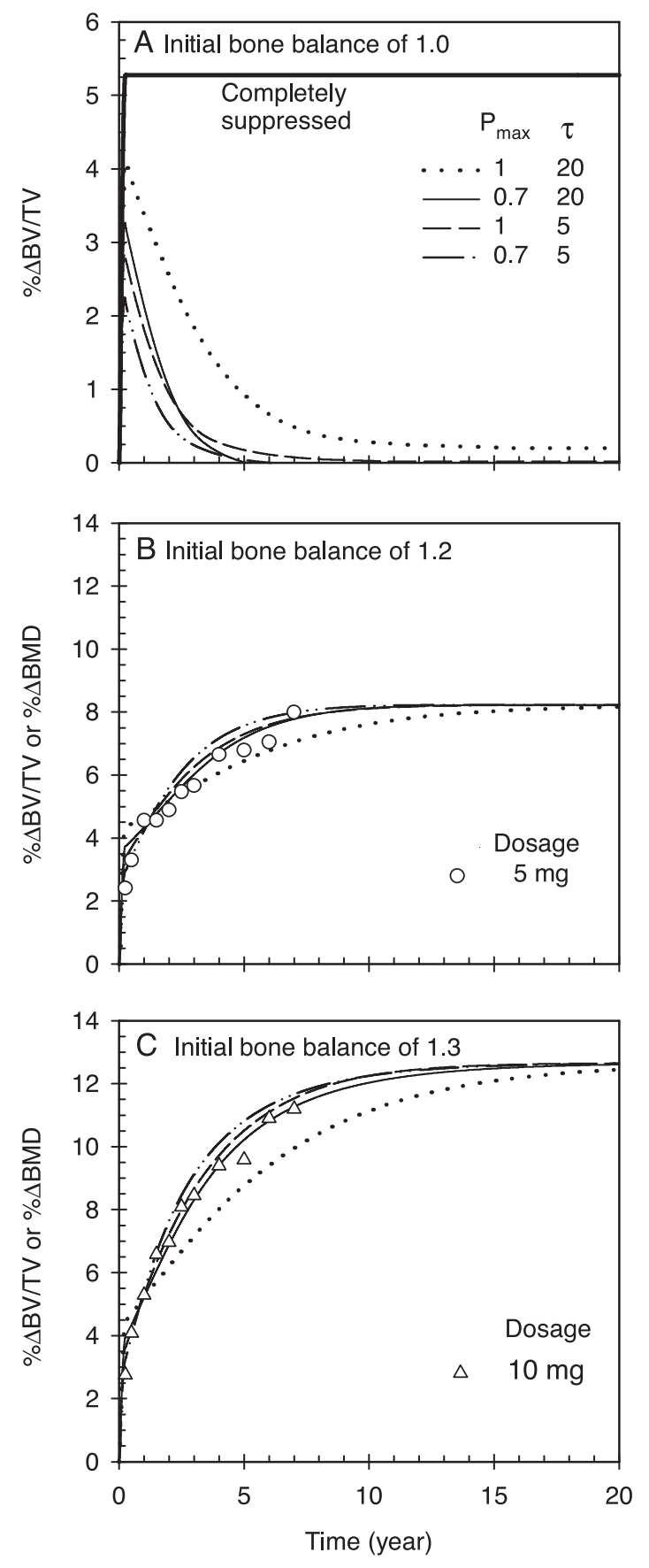

Fig. 3. BV/TV as percent increase from baseline for different potencies of suppressing activation frequency was predicted to increase then decrease when there was no reduction in resorption area (A), but to rapidly increase over the first 3 months and then gradually approach an asymptote when the resorption area is reduced by $1 / 6$ (B). The gain in bone volume was greater for a $3 / 13$ reduction in resorption area (C). Corresponding clinical data obtained from Tonino et al. [43] are shown for $5 \mathrm{mg}$ (B, circles) and $10 \mathrm{mg}$ (C, triangles) dosages.

was incompletely suppressed (Fig. 4A). Coupling incomplete activation frequency suppression with a reduction in resorption area, microdamage initially accumulated but then decreased slightly in the long term, except in the case of high suppression (Fig. 4B). With further diminishment of resorption area, which improves bone balance, microdamage decreased further, irrespective of potency (Fig. 4C). This happened because, as the resulting positive bone balance increased bone volume (Fig. 3C), strain and $\Phi$
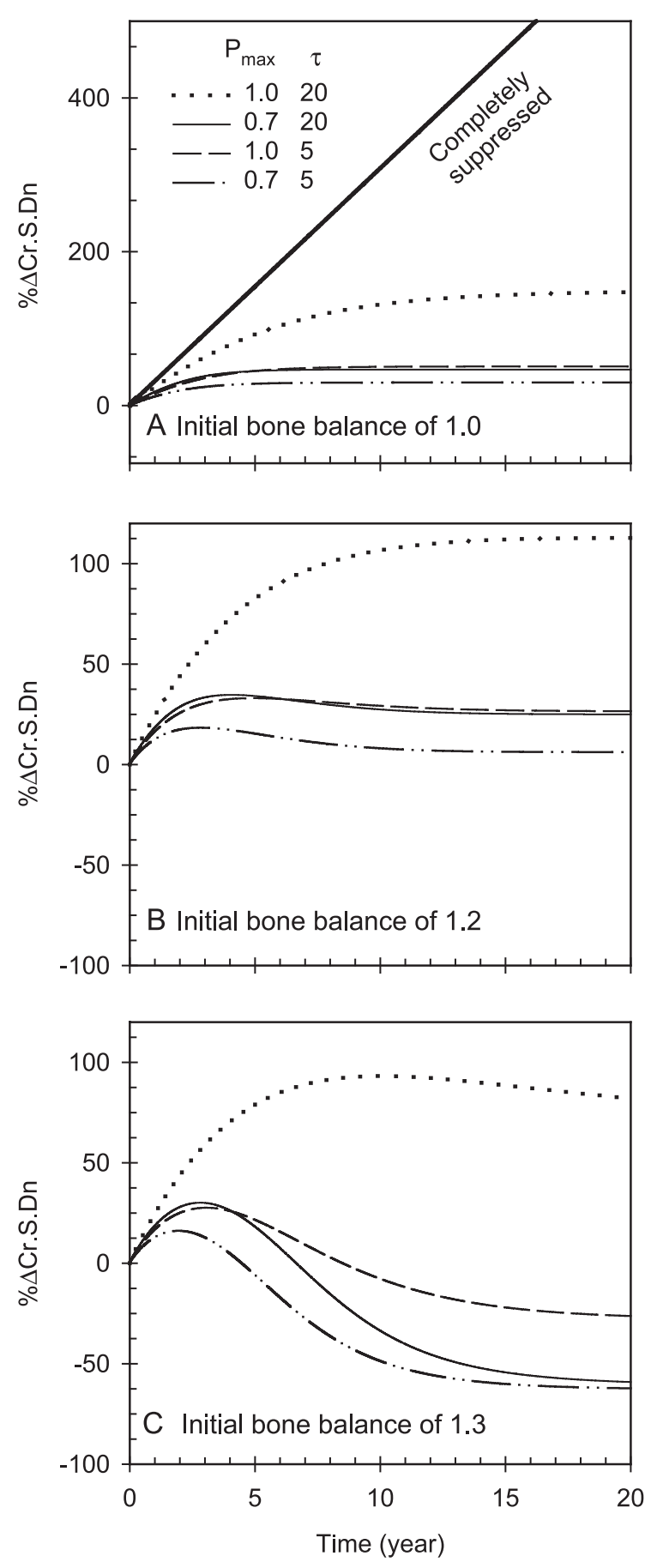

Fig. 4. Percent increase in microdamage (calculated as crack length per unit area) is unlimited when bone resorption is completely suppressed or limited when bone resorption is incompletely suppressed (A). The level of microdamage accumulation is greater for higher potency of activation frequency suppression and resorption area is reduced by $1 / 6(\mathrm{~B})$, but in the long term microdamage may fall below pretreatment level with intermediate or low potency suppression and $3 / 13$ reduction in resorption area (C). 
declined (Eqs. 1-3), decreasing damage formation (Eq. (5)). In addition, the diminished $\Phi$ increased remodeling activity over time (Fig. 5C) via the disuse response, which in turn
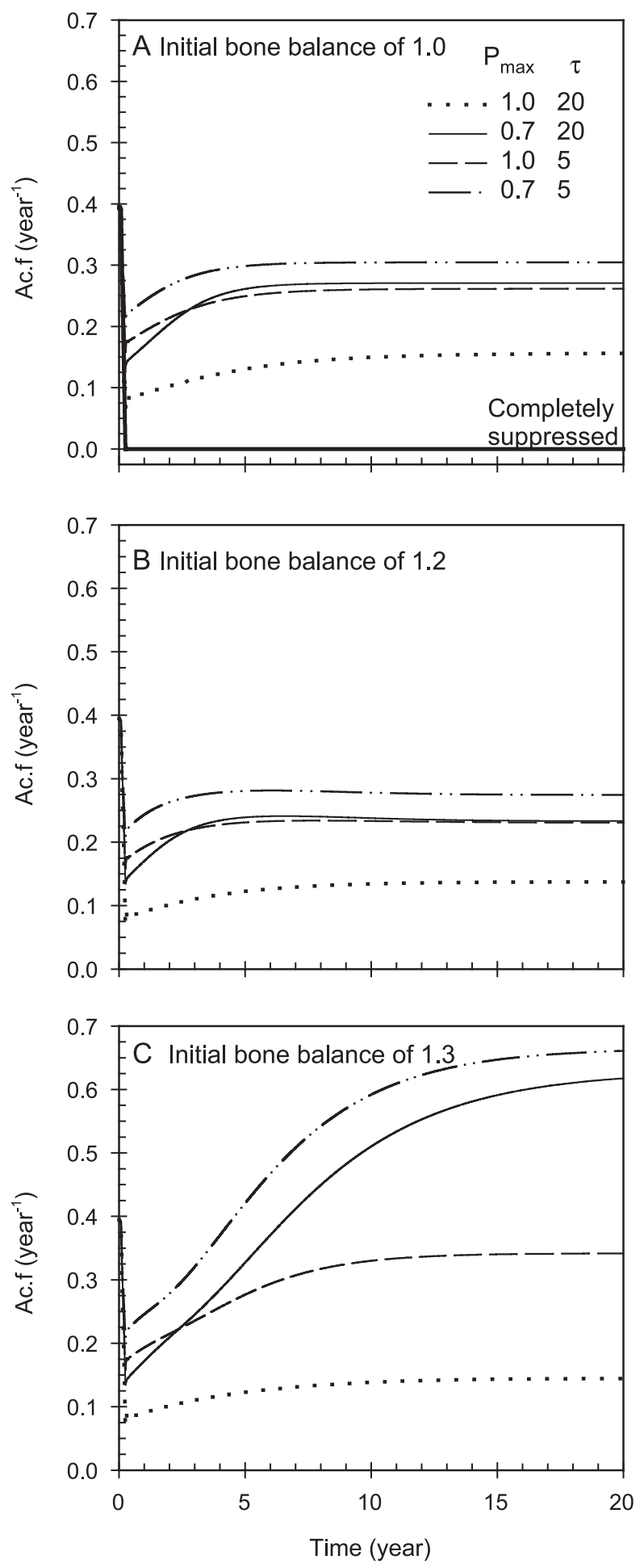

Fig. 5. Activation frequency (expressed as mineralizing surface per bone surface per year) has a greater decrease for a greater suppression of bone resorption (A). Activation frequency has a greater rebound for lower potency (B). In the case of a $3 / 13$ reduction in resorption area, activation frequency may exceed pretreatment values when the theoretical maximum potency is equal to $0.7(\mathrm{C})$. increased damage removal (Eq. 4). Thus, even though a smaller resorption space is likely to remove less damage, this effect can be overridden by the reduction in strain and damage formation associated with increased bone mass. Lowering the maximum theoretical potency $P_{\max }$ to 0.7 , combined with improved bone balance, decreased microdamage accumulation to the point that microdamage eventually fell below its initial value (Fig. 4C), and activation frequency climbed above its initial value (Fig. 5C). However, a potent bisphosphonate (e.g., $P_{\max }=1.0$ and $\tau_{\mathrm{s}}=20$ ) did not lower damage accumulation (Figs. 4 and 5B) because a greater suppression of remodeling activity results in fewer numbers of resorbing BMUs compared to a weak bisphosphonate (e.g., $P_{\max }=0.7$ and $\tau_{\mathrm{s}}=5$ ).

\section{Discussion}

To gain a better understanding of the long-term contributions of bisphosphonate effects on bone mass and microdamage accumulation, a computer model simulated the effects of suppressing BMU activation frequency and reducing BMU resorption on bone remodeling under the influence of three fundamental stimuli: mechanical disuse, estrogen deficiency, and fatigue microdamage. Based on the model's predictions, a drug that (1) does not completely suppress remodeling activation and (2) creates a positive bone balance at the BMU level by reducing resorption size may permanently increase bone volume (and hence mass and strength) with limited microdamage accumulation. The model also predicts that the effects of bisphosphonate treatment on bone mass and microdamage may require a decade or more to reach a new equilibrium.

By combining the remodeling stimuli of mechanical disuse, estrogen deficiency, and fatigue damage, the bone remodeling simulations of the present study demonstrated the potential contributions of microdamage accumulation and disuse as important mechanisms affecting the long-term effects of bisphosphonate treatment on bone volume. Specifically, the immediate bisphosphonate effects of reduced remodeling space and suppressed remodeling activation frequency resulted in lowered strain (due to an increase in $\mathrm{BV} / \mathrm{TV}$ ) and increased microdamage (due to a reduction in damage removal), respectively. These consequences, in turn, stimulated activation frequency (Fig. 5) and through the disuse pathway decreased bone formation (i.e., reduced the BMU level bone balance ratio). Thus, when simulating less than complete suppression of bone resorption with a decrease in activation frequency but no change in BMU level erosion (Rs.Ar), reduced strains and increased microdamage caused a transient increase in BV/TV with little or no longterm bone gain. Furthermore, the simulations emphasized the importance of reduced resorption area as an important contributor to long-term gains in bone volume and the importance of the disuse response in causing the plateau of bone gain. 
In contrast, previous models [12-15], which did not include the mechanical remodeling stimuli of disuse and damage, predicted only permanent bone gain. In addition, unlimited linear increases in bone mass (i.e., no plateau) occurred over the long term when there was a fixed reduction in activation frequency with positive bone turnover within the BMU $[12,13]$. Authors of earlier computational studies attributed the asymptotic limit to increases in bone mass following inhibition of bone resorption to the closure and mineralization of a portion of the remodeling space $[14,44]$. Activation frequency, not BMU level resorption, was interpreted to have the greatest influence on changes in bone mass [14]. Notably, in the bisphosphonate simulation by Hernandez et al. [13] that incorporated a secondary mineralization period with a neutral bone balance ratio, a plateau of bone gain occurred that matched a 7-year clinical observation. This study suggested that mineralization as a function of remodeling activity may be the primary contributor to bone mass gains following bisphosphonate treatment. However, the present study suggests that clinically observed gains in bone mass (Figs. 3B and 3C) may also be achieved through a positive shift in the BMU level bone balance, and this bone gain would reach a plateau when equilibrium is achieved among remodeling activity, mechanical disuse, and microdamage.

Consistent with previous simulations $[13,44]$, the magnitude of the initial bone gain was dependent on the potency of activation frequency suppression and changes in the BMU level bone balance. Further, the magnitude of the secondary or long-term bone gain was also strongly dependent on the bone balance [13] with the initial increase in bone volume depending on the remodeling conditions before treatment [12].

There is evidence from animal studies that bisphosphonate treatment increases bone volume as indicated by the model, but the time course for these increases is not known because of the invasive nature of such measurements. In addition, while posttreatment increases in BV/TV, as measured histomorphometrically at one time point, were not statistically significant in human transiliac biopsy studies, this lack of significance may be due to an insufficient sample size [45]. Nonetheless, with quantitative computed tomography of ex vivo specimens, bisphosphonates were found to significantly increase BV/TV. For example, increases in trabecular thickness and BV/TV as well as decreases in trabecular separation have been observed for the vertebrae of normal, skeletally mature dogs treated with bisphosphonates $[9,46]$. With regards to estrogen-deficient bone, ovariectomized (Ovx) rats treated with either tiludronate or ibandronate had significantly greater BV/TV than the Ovx controls $[47,48]$. In addition, Ovx minipigs treated with risedronate were found to have significantly greater BV/TV than the Ovx controls [49].

The present model predicted a limited increase in microdamage that was proportionate to activation frequency suppression. While a search of the literature does not reveal any measurements of microdamage following bisphosphonate treatment in humans, four times more microdamage (as Cr.S.Dn) was observed in the second lumbar vertebra from normal beagles treated daily for 1 year with $1.0 \mathrm{mg} \mathrm{kg}^{-1}$ of alendronate (causing a 95\% suppression of activation frequency) than in the control group [9]. Furthermore, three times more microdamage was observed in the second thoracic vertebra from beagles treated daily for 3 years with $0.3 \mathrm{mg} \mathrm{kg}^{-1} \mathrm{day}^{-1}$ of incadronate (67\% suppression of activation frequency) than in the control group [10]. It is unclear whether the increases in microdamage in the years immediately following the initiation of treatment, as either predicted by the model or experimentally observed, would increase the propensity of bone to fracture. Comparing the vertebral fracture occurrence after 7 years of a clinical trial with alendronate $(6.2 \%$ at $5 \mathrm{mg}$ and $6.6 \%$ at $10 \mathrm{mg})$ to the occurrence after the trial's first 3 years $(2.9 \%$ at $5 \mathrm{mg}$ and $2.8 \%$ at $10 \mathrm{mg}$ ) suggests that the fracture risk in bisphosphonate-treated, postmenopausal women increases over time $[43,50]$. This trend may be due to increases in fatigue microdamage and brittleness caused by the pharmacologic decrease in remodeling. Such increases have been associated with a decrease in cortical bone toughness [51,52]. In addition, the toughness of vertebral bone following bisphosphonate treatment was $20-40 \%$ less than the toughness of control bone in dog studies [9,10]. Age-related changes in bone (e.g., weakening of the collagen network) could also explain the increase in fracture with increase in treatment time. Nonetheless, the model suggests that greater potency in suppressing BMU activation frequency could prolong elevated microdamage.

As previously stated, the present model simulates clinically observed increases in BMD (Figs. 3B and 3C), though it does not account for the contribution of secondary mineralization. With a reduction in the bone turnover rate following bisphosphonate treatment, BMU bone packets have more time to mineralize before they are replaced [13]. The expectation that this would contribute to increased BMD is supported by quantitative microradiography and backscattered electron scanning of transiliac biopsies from postmenopausal women, which showed that 3 years of alendronate treatment significantly increased and homogenized mineral content in the iliac crest $[53,54]$. Bisphosphonate-induced changes in BMU level bone balance and secondary mineralization are likely additive in their effects on BMD. A lack of secondary mineralization in the model complicates the direct comparison of its predicted changes in $\mathrm{BV} / \mathrm{TV}$ to clinical changes in BMD. However, its predictions about the long-term effects of bisphosphonate treatment on $\mathrm{BV} / \mathrm{TV}$ should parallel the expectations for increased BMD.

As with any theoretical study, the present results must be interpreted in light of the limiting assumptions. First, it was assumed that bisphosphonates would not affect the targeting of BMUs to remove damage in the model (i.e., the specificity factor $F_{\mathrm{s}}$ in Eq. (4) was kept constant). This is 
inconsistent with the observation by Li et al. [55] that the association of resorption spaces with microdamage was reduced by alendronate treatment. Thus, the model may have overpredicted damage removal. Second, a bone modeling response was not included. One mechanism to prevent fracture when significant fatigue microdamage is present in bone is periosteal bone formation, which lowers the stress. Mashiba et al. [56] observed that the ribs of alendronatetreated dogs had increased the cortical area as well as microdamage, and the present model did not replicate the protection afforded by such modeling. If such a response was included by reducing the stress on the representative volume $(\sigma<1 \mathrm{MPa})$, damage formation would have been less. Third, decreases or increases in loading activity that may occur with aging or exercising were not studied in this initial analysis, although the model has the capacity to incorporate such effects. Clearly, such changes could affect the bone volume and microdamage responses associated with bisphosphonate treatment. Fourth, BMU level bone formation was assumed to equal bone resorption at the start of treatment. While the representative bone volume had experienced a history of a negative imbalance (when estrogen withdrawal was simulated to create the initial postmenopausal remodeling conditions), the model was allowed to run for 15 years without treatment and a new quasi-equilibrium state was reached. Clearly, assuming an initial bone balance of 1 (to reduce complexity) may not accurately represent clinical postmenopausal, osteoporotic bone. It is perhaps more likely that the initial bone balance would be less than 1 (i.e., formation is less than resorption). Because the control of bone balance in the model is multifaceted, bisphosphonate effects on bone initially in a state of negative turnover at the BMU level would depend on what caused this effect (e.g., decrease in loading, increase in the mechanostat set point, or some other factor negatively impacting osteoblast function). Lastly, irreversible bone loss due to trabecular perforations, an important mechanism in the development of osteoporosis [15], was not modeled. Including such an effect would increase strain and damage formation.

Despite the assumptions and simplifications, the present study illustrates the potential significance of designing antiresorptive drugs that allow BMU level resorption and BMU activation suppression to be independently controlled. On one hand, it is important to maintain bone turnover so as to prevent damage accumulation. On the other hand, it is important to control the size of the resorption space so as to achieve better bone balance and reduce the risk of trabecular perforation. The ideal anti-resorptive agent would produce a positive bone balance at the BMU level by decreasing erosion without substantially decreasing BMU activation frequency. While reducing erosion depth would diminish the effectiveness of damage removal by remodeling to some extent, the present model suggests that the achievement of a positive bone balance would ultimately control damage formation by reducing bone strain.

\section{Acknowledgments}

Both the Dissertation Year Fellowship from Floyd and Mary Schwall and the Achievement Rewards for College Scientists from the Northern California Chapter of the ARCS foundation, Inc. provided monetary assistance for the present research. We thank Chris Hernandez for insightful discussions about bisphosphonates and bone remodeling, Juan Rodrigo for supporting the research efforts of JSN, and the Berkeley Orthopaedic Biomechanics Laboratory for providing the computer graphic of a volume of trabecular bone.

\section{References}

[1] Rogers MJ, Watts DJ, Russell RG. Overview of bisphosphonates. Cancer 1997;80:1652-60.

[2] Sato M, Grasser W, Endo N, Akins R, Simmons H, Thompson DD, et al. Bisphosphonate action. Alendronate localization in rat bone and effects on osteoclast ultrastructure. J Clin Invest 1991;88:2095-105.

[3] Lin JH. Bisphosphonates: a review of their pharmacokinetic properties. Bone 1996;18:75-85.

[4] Fleisch H. Bisphosphonates: mechanisms of action. Endocr Rev 1998;19:80-100.

[5] Breuil V. Mechanisms of action of bisphosphonates. Rev Rhum Engl Ed 1999;66:339-43.

[6] Rodan GA. Mechanisms of action of bisphosphonates. Annu Rev Pharmacol Toxicol 1998;38:375-88.

[7] Rodan GA, Fleisch HA. Bisphosphonates: mechanisms of action. J Clin Invest 1996;97:2692-6.

[8] Tobias JH. How do bisphosphonates prevent fractures? Ann Rheum Dis 1997;56:510-1.

[9] Mashiba T, Turner CH, Hirano T, Forwood MR, Johnston CC, Burr DB. Effects of suppressed bone turnover by bisphosphonates on microdamage accumulation and biomechanical properties in clinically relevant skeletal sites in beagles. Bone 2001;28:524-31.

[10] Komatsubara S, Mori S, Mashiba T, Ito M, Li J, Kaji Y, et al. Longterm treatment of incadronate disodium accumulates microdamage but improves the trabecular bone microarchitecture in dog vertebra. J Bone Miner Res 2003;18:512-20.

[11] Burr DB, Forwood MR, Fyhrie DP, Martin RB, Schaffler MB, Turner $\mathrm{CH}$. Bone microdamage and skeletal fragility in osteoporotic and stress fractures. J Bone Miner Res 1997;12:6-15.

[12] Heaney RP, Yates AJ, Santora II AC. Bisphosphonate effects and the bone remodeling transient. J Bone Miner Res 1997;12:1143-51.

[13] Hernandez CJ, Beaupré GS, Marcus R, Carter DR. A theoretical analysis of the contributions of remodeling space, mineralization, and bone balance to changes in bone mineral density during alendronate treatment. Bone 2001;29:511-6.

[14] Lacy ME, Bevan JA, Boyce RW, Geddes AD. Antiresorptive drugs and trabecular bone turnover: validation and testing of a computer model. Calcif Tissue Int 1994;54:179-85.

[15] Thomsen JS, Mosekilde L, Boyce RW, Mosekilde E. Stochastic simulation of vertebral trabecular bone remodeling. Bone 1994;15: $655-66$.

[16] Giangregorio L, Blimkie CJ. Skeletal adaptations to alterations in weight-bearing activity: a comparison of models of disuse osteoporosis. Sports Med 2002;32:459-76.

[17] Frost HM. The mechanostat: a proposed pathogenic mechanism of osteoporoses and the bone mass effects of mechanical and nonmechanical agents. Bone Miner 1987;2:73-85.

[18] Riggs BL, Khosla S, Melton III LJ. Sex steroids and the construction and conservation of the adult skeleton. Endocr Rev 2002;23:279-302. 
[19] Tomkinson A, Gevers EF, Wit JM, Reeve J, Noble BS. The role of estrogen in the control of rat osteocyte apoptosis. J Bone Miner Res 1998; $13: 1243-50$.

[20] Tomkinson A, Reeve J, Shaw RW, Noble BS. The death of osteocytes via apoptosis accompanies estrogen withdrawal in human bone. J Clin Endocrinol Metab 1997;82:3128-35.

[21] Zaman G, Cheng MZ, Jessop HL, White R, Lanyon LE. Mechanical strain activates estrogen response elements in bone cells. Bone 2000; 27:233-9.

[22] Mori S, Burr DB. Increased intracortical remodeling following fatigue damage. Bone 1993;14:103-9.

[23] Verborgt O, Gibson GJ, Schaffler MB. Loss of osteocyte integrity in association with microdamage and bone remodeling after fatigue in vivo. J Bone Miner Res 2000;15:60-7.

[24] Hazelwood SJ, Martin RB, Rashid MM, Rodrigo JJ. A mechanistic model for internal bone remodeling exhibits different dynamic responses in disuse and overload. J Biomech 2001;34:299-308.

[25] Turner CH, Anne V, Pidaparti RM. A uniform strain criterion for trabecular bone adaptation: do continuum-level strain gradients drive adaptation? J Biomech 1997;30:555-63.

[26] Beaupré GS, Orr TE, Carter DR. An approach for time-dependent bone modeling and remodeling-application: a preliminary remodeling simulation. J Orthop Res 1990;8:662-70.

[27] Huiskes R, Weinans H, van Rietbergen B. The relationship between stress shielding and bone resorption around total hip stems and the effects of flexible materials. Clin Orthop 1992;274:124-34.

[28] Martin B. Mathematical model for repair of fatigue damage and stress fracture in osteonal bone. J Orthop Res 1995;13:309-16.

[29] Burr DB, Martin RB. Calculating the probability that microcracks initiate resorption spaces. J Biomech 1993;26:613-6.

[30] Carter DR, Caler WE. A cumulative damage model for bone fracture. J Orthop Res 1985;3:84-90.

[31] Martin RB. Porosity and specific surface of bone. Crit Rev Biomed Eng 1984;10:179-222.

[32] Bentolila V, Boyce TM, Fyhrie DP, Drumb R, Skerry TM, Schaffler MB. Intracortical remodeling in adult rat long bones after fatigue loading. Bone 1998;23:275-81.

[33] Parfitt AM. The physiologic and clinical significance of bone histomorphometric data. In: Recker RR, editor. Bone histomorphometry: techniques and interpretation, vol. 143. Boca Raton: CRC Press Inc.; 1983. p. 223.

[34] Frost HM. On rho, a marrow mediator, and estrogen: their roles in bone strength and "mass" in human females, osteopenias, and osteoporoses-Insights from a new paradigm. J Bone Miner Metab 1998; $16: 113-23$.

[35] Frost HM. On the estrogen-bone relationship and postmenopausal bone loss: a new model. J Bone Miner Res 1999;14:1473-7.

[36] Recker R, Lappe J, Davies K, Heaney R. Characterization of perimenopausal bone loss: a prospective study. J Bone Miner Res 2000;15: 1965-73.

[37] Bravenboer N, Papapoulos SE, Holzmann P, Hamdy NA, Netelenbos JC, Lips P. Bone histomorphometric evaluation of pamidronate treatment in clinically manifest osteoporosis. Osteoporos Int 1999;9: 489-93.

[38] Chavassieux PM, Arlot ME, Reda C, Wei L, Yates AJ, Meunier PJ. Histomorphometric assessment of the long-term effects of alendronate on bone quality and remodeling in patients with osteoporosis. J Clin Invest 1997;100:1475-80.

[39] Chavassieux PM, Arlot ME, Roux JP, Portero N, Daifotis A, Yates AJ, et al. Effects of alendronate on bone quality and remodeling in glucocorticoid-induced osteoporosis: a histomorphometric analysis of transiliac biopsies. J Bone Miner Res 2000;15:754-62.
[40] Storm T, Steiniche T, Thamsborg G, Melsen F. Changes in bone histomorphometry after long-term treatment with intermittent, cyclic etidronate for postmenopausal osteoporosis. J Bone Miner Res 1993; 8:199-208

[41] Eriksen EF, Melsen F, Sod E, Barton I, Chines A. Effects of long-term risedronate on bone quality and bone turnover in women with postmenopausal osteoporosis. Bone 2002;31:620-5.

[42] Porras AG, Holland SD, Gertz BJ. Pharmacokinetics of alendronate. Clin Pharmacokinet 1999;36:315-28.

[43] Tonino RP, Meunier PJ, Emkey R, Rodriguez-Portales JA, Menkes CJ, Wasnich RD, et al. Skeletal benefits of alendronate: 7-year treatment of postmenopausal osteoporotic women. Phase III Osteoporosis Treatment Study Group. J Clin Endocrinol Metab 2000;85:3109-15.

[44] Heaney RP. The bone-remodeling transient: implications for the interpretation of clinical studies of bone mass change. J Bone Miner Res 1994;9:1515-23.

[45] Hauge EM, Mosekilde L, Melsen F, Frydenberg M. How many patients are needed? Variation and design considerations in bone histomorphometry. Bone 2001;28:556-62.

[46] Hu JH, Ding M, Soballe K, Bechtold JE, Danielsen CC, Day JS, et al. Effects of short-term alendronate treatment on the three-dimensional microstructural, physical, and mechanical properties of dog trabecular bone. Bone 2002;31:591-7.

[47] Barbier A, Martel C, de Vernejoul MC, Tirode F, Nys M, Mocaer G, et al. The visualization and evaluation of bone architecture in the rat using three-dimensional X-ray microcomputed tomography. J Bone Miner Metab 1999;17:37-44.

[48] Bauss F, Lalla S, Endele R, Hothorn LA. Effects of treatment with ibandronate on bone mass, architecture, biomechanical properties, and bone concentration of ibandronate in ovariectomized aged rats. J Rheumatol 2002;29:2200-8.

[49] Borah B, Dufresne TE, Chmielewski PA, Gross GJ, Prenger MC, Phipps RJ. Risedronate preserves trabecular architecture and increases bone strength in vertebra of ovariectomized minipigs as measured by three-dimensional microcomputed tomography. J Bone Miner Res 2002;17:1139-47.

[50] Liberman UA, Weiss SR, Broll J, Minne HW, Quan H, Bell NH, et al. Effect of oral alendronate on bone mineral density and the incidence of fractures in postmenopausal osteoporosis. The Alendronate Phase III Osteoporosis Treatment Study Group. N Engl J Med 1995;333: $1437-43$

[51] Currey JD, Brear K, Zioupos P. The effects of ageing and changes in mineral content in degrading the toughness of human femora. J Biomech 1996;29:257-60.

[52] Zioupos P. Accumulation of in-vivo fatigue microdamage and its relation to biomechanical properties in ageing human cortical bone. J Microsc 2001;201:270-8.

[53] Roschger P, Rinnerthaler S, Yates J, Rodan GA, Fratzl P, Klaushofer $\mathrm{K}$. Alendronate increases degree and uniformity of mineralization in cancellous bone and decreases the porosity in cortical bone of osteoporotic women. Bone 2001;29:185-91.

[54] Boivin GY, Chavassieux PM, Santora AC, Yates J, Meunier PJ. Alendronate increases bone strength by increasing the mean degree of mineralization of bone tissue in osteoporotic women. Bone 2000;27:687-94

[55] Li J, Mashiba T, Burr DB. Bisphosphonate treatment suppresses not only stochastic remodeling but also the targeted repair of microdamage. Calcif Tissue Int 2001;69:281-6.

[56] Mashiba T, Hirano T, Turner CH, Forwood MR, Johnston CC, Burr DB. Suppressed bone turnover by bisphosphonates increases microdamage accumulation and reduces some biomechanical properties in dog rib. J Bone Miner Res 2000;15:613-20. 